meantime we must remember that the outcome of trauma is lasting. Forgetting something we wish was not true is only too easy.

CAROLINE GARLAND

Psychoanalyst

Tavistock Clinic,

London NW3 5BA
1 Choy T, de Bosset F Post-traumatic stress disorder: an overview Can f Psychiatr. 1992;37:578-83. Garland C. External trauma and the internal world: an approach to understanding survivors. In: Holmes J, ed. Textbook of Psychotherapy in Psychiatric Practice London: Churchill Livingstone, 991:507-32

3 Krystal H, ed. Massive psychic trauma New York: International University Press, 1968

4 Jucovy ME. Psychoanalytic contributions to holocaust studies. In $\mathcal{Y}$ Psychoanal 1992;73:267-82

5 Freud S. Mourning and Melancholia. Standard edition. Vol 14. London: Hogarth Press, 1915.

6 Lewis DO. From abuse to violence: psychophysiological consequences of maltreatment. $9 \mathrm{Am} \mathrm{Acad}$ Child Adolesc Psychiatry 1992;31:383-91.

\title{
The health of the nation's research and development
}

\author{
Time for some action
}

The Health of the Nation singled out five areas for special attention and set out a method to ensure that applied research would lead directly to better health in each of them. ${ }^{\prime}$ Another document, Research for Health, was launched last week by the secretary of state for health. ${ }^{2}{ }^{3}$ It summarises the progress and charts the direction of the Department of Health's strategy for research and development. This "places collective responsibility on the research community" and requires "a more robust and productive relationship between health problems and scientific investigation." It considers that "the imbalance between investigator-led research and problem-led research has resulted in insufficient attention being paid to a wide range of issues germane to health sector demands." This is only too true, but the problem does not lie with the clinical research community, many members of which have been trying for years to gain funding and academic recognition for projects that we would now call research and development.

Interestingly, in the same week that Research for Health was published the first project funded by the Department of Health's research and development programme has appeared in print. The Health Survey for England 1991 is a report by the Social Survey Division of the Office of Population Censuses and Surveys. ${ }^{+}$Although this report is obviously important for its content, it will also be read to see what light it sheds on the Department of Health's attitude to the spending of funds for research and development.

Concerned solely with cardiovascular disease, the survey describes a cross sectional sample of 3242 men and women aged over 16 in England who were studied in 1991 by questionnaire, examination, and blood sampling. The document provides details of height and indices of obesity and shows, for example, that, compared with the dietary survey of $1986-7,{ }^{5}$ the proportion of men who are obese (that is, have a body mass index $>30 \mathrm{~kg} / \mathrm{m}^{2}$ ) has increased from $7 \%$ to $13 \%$; the proportion of obese women has increased from $12 \%$ to $15 \%$.

The national mean blood pressure in men was $140 / 78$ $\mathrm{mm} \mathrm{Hg}$, and the report provides unsurprising data such as those showing a rise in pressure with age and an association with alcohol consumption. The survey found that about $70 \%$ of men and women had total blood cholesterol concentrations above the "desirable" figure of $5.2 \mathrm{mmol} / \mathrm{l}$. As for smoking habit, $30 \%$ of men and women were currently cigarette smokers, with $13 \%$ of men and $10 \%$ of women smoking more than 20 cigarettes a day. And so on through alcohol consumption, physical activity, and self reported general health and prevalence of cardiovascular disease.

The information on weight augurs ill for the Department of Health's target A.7, which is to reduce the proportion of the population who are obese by a quarter over the next decade. ${ }^{5}$ On the other hand, target A.6 is to reduce the mean systolic blood pressure in the adult population by at least $5 \mathrm{~mm} \mathrm{Hg}$ by the year 2005, and this may now be seen to be unnecessarily enthusiastic. Although the Health Survey for England emphasises the importance of knowing about baselines before setting targets, it does not help us to decide what sensible targets are. Nor do baseline data, however detailed and sophisticated, take into account the fact that with increasing knowledge targets change-for example, even the Americans are beginning to believe that "we should draw back from universal screening and treatment of blood cholesterol."'

The Health Survey of England will therefore be seen-at least as it stands - to be a somewhat pedestrian document. Its importance will undoubtedly increase as the survey is repeated and the number of subjects is increased (to 17000 this year). The most interesting results from this first survey, however, are the comparisons with earlier data collected in other ways, which underline the fact that this is just one more survey. True, it is more extensive than others (or will be) and it covers a wider age range and is therefore more representative of the whole population. But in essence this survey is unlikely to provide very different information from the British regional heart survey, ${ }^{7}$ other British surveys, ${ }^{8-11}$ or the World Health Organisation's MONICA project, ${ }^{12}$ which began in 1980. There have been enough similar surveys in other countries to provide a cross check on surveys done in the British population. ${ }^{1314}$ The important point is that the Health Survey for England contains nothing new, no big idea. Does $R \& D$ really mean Research is Dull?

Many clinical academics are totally disillusioned by the Universities Funding Council and its research ratings, which award brownie points mainly for laboratory based research. Clinicians are looking to the Department of Health's new research and development strategy to re-establish the importance of research programmes related to clinical work.

But if a thousand flowers are to bloom we must be wary of too much centralised direction. The track record of targeted research is not all that impressive: who remembers President Nixon's "Let's conquer cancer in the 70s"? A government dedicated in all other matters to the "supply side" must not equate "investigator led" with "inappropriate" research. It is clearly sensible to define priority areas and for fundholders to consider proposals for research from the academic supply side. It is not so obviously sensible for all research and development funding to be spent on projects defined to the last detail at the centre.

So far the research and development strategy seems to have been composed of talks about talks at the highest level followed by the production of glossy brochures, which may be educational but are a glimpse of the obvious to those in the field. What we need now are various clinical projects up and running, funded under the umbrella of research and develop- 
ment. The Health Survey for England 1991 is a start, but perhaps not a very auspicious one, for research and development. Clinicians will be watching this space with interest.

J R HAMPTON

Division of Cardiovascular Medicine,

Professor of cardiology

University Hospital

Queen's Medical Centre,

Nottingham NG7 2UH

1 Department of Health. The health of the nation: a strategy for health in England. London: DoH, 1992 (CM 1986.)

2 Department of Health. Research for health. London: DoH, 1993.

3 Delamothe T. DoH goes in search of useful knowledge. BMf 1993;307:84

Office of Population Censuses and Surveys, Social Survey Division. Health survey for England 1991. London: HMSO, 1993.

5 Department of Health. Specification of national indicators. London: HMSO, 1992.
6 Hulley SB, Walsh MB, Newman TB. Health policy on blood cholesterol. Time to change directions. Circulation 1992;86:1026-9.

Shaper AG, Cook DG, Walker M, Macfarlane PW. Prevalence of ischaemic heart disease in middle aged British men. Br Heart f 1984;51:595-605.

8 Rose G, Shipley M. Plasma cholesterol concentration and death from coronary heart disease: 10 year results of the Whitehall study. $B M J$ 1986;293:306-7.

Smith WCS, Kenicer MB, Tunstall-Pedoe H, Clark EC, Crombie IK. Prevalence of coronary heart disease in Scotland: Scottish heart health study. Br Heart f 1990;64:295-8.

10 Elwood PC, Yarnell JWG, Pickering J, Fehily AM, O'Brien JR. Exercise, fibrinogen, and other risk factors for ischaemic heart disease. Caerphilly prospective heart disease study. Br Heart $f$ risk factors for

11 Morris JN, Clayton DG, Everitt MG, Semmence AM, Burgess EH. Exercise in leisure time: coronary attack and death rates. Br Heart f 1990;63:325-34.

12 Tunstall-Pedoe $\mathrm{H}$. The World Health Organization MONICA Project (monitoring trends and determinants in cardiovascular disease): a major international collaboration. $f$ Clin Epidemiol 1988;41:105-14

13 Anderson KM, Castelli WP, Levy D. Cholesterol and mortality. 30 Years of follow-up from the Framingham study. IAMA 1987;257:2176-80.

14 Tuomilehto J, Arstila M, Kaarsaloe E, Kankaanpaa J, Ketonen M, Kuulasmaa K, et al. Acute myocardial infarction (AMI) in Finland - baseline data from the FINMONICA AMI register in 1983-1985. Eur Heart f 1992;13:577-87.

\section{Hand transmitted vibration}

\section{Needs skilled assessment and more research}

A nation's wealth often results from its extraction and manufacturing industries, and from the industrial revolution until quite recently Britain has had a very successful record. But some of this success has been achieved at the cost of the health of the workers who contributed to it. An example is vibration induced white finger, now known as the hand-arm vibration syndrome. The management of this condition challenges the medical profession in general, and occupational physicians in particular. Unfortunately, few have risen to the challenge.

The use of tools that cause rapid vibration dates from about $1883,{ }^{1}$ and reports of their association with symptoms in the hands date from the early 1900s. Despite a vast amount of medical and scientific literature on hand transmitted vibration, progress in understanding the pathophysiology of the condition and thereby defining an acceptable method of assessing and managing the problem has been slow. The Faculty of Occupational Medicine's recent report on the clinical effects and pathophysiology of hand transmitted vibration $^{23}$ will hopefully increase the general level of understanding of hand transmitted vibration and improve the coordination of future research.

Arguably, legislation is now the main stimulus to increase our knowledge of the condition. Since 1985 vibration white finger has been a prescribed disease, meaning that its occurrence in association with certain occupations may give rise to compensation by the state. Workers may also take action against their employers in the civil courts. A survey conducted by the Health and Safety Executive in the 1980s estimated that about 130000 manufacturing workers were exposed to hand transmitted vibration for relatively long periods and that in the construction industry 22000 workers were exposed on any one day. ${ }^{45}$

As workers and their associations have become increasingly litigious the demand for medical assessments of hand transmitted vibration has increased considerably. There is also the need for employers to comply with health and safety legislation. The Health and Safety at Work Act requires them to do all that is reasonably practicable to safeguard their employees' health. ${ }^{6}$ Since the beginning of this year the Management of Health and Safety Regulations have specified the duties of employers to make suitable and sufficient assessments of hazards and risk in the workplace and to ensure that appropriate health surveillance is carried out.
Further legislation is expected in the light of a European Community directive on physical hazards in the workplace.

Currently, the diagnosis of the hand-arm vibration syndrome relies on a good history. This is necessary to establish the nature of the presenting complaint, obtain a history of exposure to vibration, and exclude other possible causes of the symptoms. Previously, attention was focused on the vascular changes in the hands. Current opinion suggests that the syndrome is not just Raynaud's phenomenon due to vibration; it is a more complex response in which neurological changes are as important as, if not more, important than, the vascular ones.

Relying on the result of a simple cold provocation test is no longer acceptable to confirm the diagnosis of the hand-arm vibration syndrome. Clinical assessment should be supported by special investigations of vascular and neurological function, which may require referral to a specialist. Cold provocation tests that include measurement of systolic blood pressure in the finger are considered valuable. ${ }^{58}$ Carefully performed cold water immersion tests using thermistors before, during, and after immersion may also be useful to confirm the presence of vasospasm and grade its severity. ${ }^{5}$ Recommended tests of neurological function include aesthesiometry and measurements of vibrotactile and temperature thresholds. ${ }^{2}$ Neurophysiological tests are particularly useful for detecting the presence of entrapment neuropathies and other neuropathies not related to work.

The faculty's report recommends the establishment of a standing committee on the medical aspects of vibration. This would seem desirable to coordinate multidisciplinary activity with communication within the medical profession and to regulatory bodies. The assessment of the hand-arm vibration syndrome needs standardising. The Taylor-Pelmear scale, which was based on the number, extent, and duration of white finger attacks and on the resultant disability, has been superseded by a revised scale, the Stockholm classification, which assesses vascular and neurological symptoms independently. Nevertheless, the original scale is still used in many medicolegal assessments. The criteria for awarding compensation, which currently ignore the neurological component of the hand-arm vibration syndrome, also need review.

We need to know more about the syndrome to protect today's generation of workers and to assess, redeploy, and 